\title{
Prediction of Polymer Flow Length by Coupling Finite Element Simulation with Artificial Neural Network
}

\author{
IONUT LAURENTIU SANDU, FLORIN SUSAC, FELICIA STAN, CATALIN FETECAU* \\ Dunarea de Jos University of Galati, Center of Excellence Polymer Processing, 47 Domneasca Str., 800008, Galati, Romania
}

\begin{abstract}
In this study, computer-aided engineering (CAE) simulation software and the design of experiments (DOE) method were used to simulate the injection molding process in terms of the melt flow length, using a spiral part. Process parameters such as melt temperature, mold temperature, injection pressure and mold cavity thickness were considered as injection molding variables. A predictive model for the flow length was created using a three-layer artificial neural network (ANN). The ANN model was trained with both simulation and experimental data, and the predictive performances were compared in terms of correlation coefficient, root mean square error and mean relative error. The cavity thickness and melt temperature were found to be the most significant factors for both the simulation and the experiment, while the injection pressure and the mold temperature had little effect on the flow length. The ANN model trained with Moldex3D data shows a significantly higher prediction capacity than the ANN model trained with experimental data. However, the melt flow lengths predicted by the ANN model for both Moldex3D and Moldflow simulation data are statistically significant, indicating that the proposed prediction methodology, which combines the ANN model, DOE method and the CAE simulation technology, can effectively predict the flow length of injection molded parts, with a small number of data.
\end{abstract}

Keywords: injection molding, flow length, simulation, Taguchi method, artificial neural network.

\section{Introduction}

Considering the demands of the injection molding industry, i.e., to produce cheaper complex parts with high quality, advanced tools and methods are necessary to deal with the injection molding process. The most efficient and cost-effective way of predicting the behavior of molten polymers during the injection molding process is to carry out numerical simulations [1-3]. Over the years, in the attempt to assist the injection molding industry, several computer-aided engineering (CAE) simulation programs have been developed, such as C-MOLD, Moldflow and Moldex3D.

By injection molding simulation it is possible, at different stages of the injection molding process (filling, packing, cooling, ejection, etc.), to obtain useful information such as flow pattern, fill time, air trap, weld lines, warpage and shrinkage, sink marks, etc. Moreover, to increase the process/part quality and productivity, the simulation of polymer flow allows the designer to change the product design before production, optimize the tool design before the first tooling, establish the processing window, reduce the number of mold trials, or perform a careful molding machine selection [1-3].

Since polymers exhibit a complex thermo-viscoelastic behavior during the injection molding process [4], the processing parameters play a major role in influencing the properties and quality of the final products [1-3]. Thus, the optimization of the injection molding parameters in conjuction with the quality characteristics can be a tedious trial and error process, which requires a large number of physical experiments [5]. Therefore, reasearchers have tried to find reliable alternative solutions to optimize the injection molding parameters in order to improve the quality characteristics of the molding parts.

Approaches such as response surface methodology [6,7], design of experiments [8], Taguchi method [9-14], surrogate model [15], genetic algorithms [6, 7], and artificial neural network model [16-24] have

\footnotetext{
* email: catalin.fetecau@ugal.ro
} 
been combined with numerical simulation and/or experimental analysis to reduce the time for optimizing the injection molding process.

The artificial neural network (ANN) has been extensively used to predict the relationship between process parameters and the quality of molded parts through shrinkage [17], warpage [16, 23-25], mechanical properties [19], part thickness [21], and weight [22].

When designing plastic parts for the injection-molding process, one of the most important aspects is to understand how the polymer fills the mold. The simulation of the filling stage is important in providing the preliminary decisions regarding the processability of the polymer, which is generally based on estimating the flow length. In addition, it is important to model the polymer flow as accurately as possible in order to design and control the injection-molding process, which will ultimately lead to the best mechanical properties of the injection-molded parts.

However, the researches cited above mostly optimized the process parameters that minimize the warpage or/and shrinkage of the parts, whereas the flow behavior greatly affecting the quality of the injection molding parts was rarely taken into consideration [26-30].

In this paper, finite element simulations are carried out under the Moldflow and Moldex3D software environments to evaluate and compare the effect of injection molding parameters such as melt and mold temperatures, injection pressure, and cavity thickness on the quality of the molded parts through the flow length - the greater the flow length, the better the flow behavior of the polymer.

To reduce the computing time, numerical simulations are carried out for combinations of process parameters designed using a 4-factor 3-level Taguchi $\mathrm{L}_{27}$ orthogonal array. A three-layer artificial neural network (ANN) model with a tangent sigmoid transfer function at the hidden layers and a linear transfer function at the output layer, trained with both simulated and experimental data, is used to predict the flow length. The flow length predicted by the neural network is compared with those obtained by simulation and experimental analysis, on independent datasets generated for selected injection molding conditions.

\section{Materials and methods}

\subsection{Materials}

In the experimental investigation, two semi-crystalline polymers were considered - namely lowdensity polyethylene (LDPE ROPOTEN ${ }^{\circledR}$ T, Lokoil), and high-density polyethylene (HDPE 277-73, KazanOrgSintez, Russia). The melt flow rate (MFR) was measured using a Melt Flow Quick Index (CEAST Model 7021-7022, Instron, USA). The tests were carried out with a load mass of $2.16 \mathrm{~kg}$ at various temperatures relevant for the injection molding process.

The Differential Scanning Calorimetry (DSC) analysis was carried out with the TA Q200 Differential Scanning Calorimeter (TA Instruments, US). In order to erase the previous thermal history, the pellets with a mass of about $10 \mathrm{mg}$, sealed in aluminum pans, were heated from $25^{\circ} \mathrm{C}$ to $250^{\circ} \mathrm{C}$ at a scanning rate of $10^{\circ} \mathrm{C} / \mathrm{min}$, and held isothermally for $5 \mathrm{~min}$. The samples were then cooled, heated and cooled again in the same temperature range, at a scanning rate of $10^{\circ} \mathrm{C} / \mathrm{min}$ in order to measure the melting, crystallization, transition and ejection temperatures. The thermal properties and the melt flow rate are listed in Table 1.

Table 1. Crystallization and melting behavior of LDPE and HDPE polymers

\begin{tabular}{lcc}
\hline \multicolumn{1}{c}{ Parameters } & LDPE & HDPE \\
\hline Melting temperature $\left({ }^{\circ} \mathrm{C}\right)$ & 115.9 & 136.5 \\
Crystallization temperature $\left({ }^{\circ} \mathrm{C}\right)$ & 95.3 & 113.2 \\
Crystallinity $(\%)^{*}$ & 21.6 & 45.7 \\
Transition temperature $\left({ }^{\circ} \mathrm{C}\right)$ & 98.2 & 117.2 \\
Ejection temperature $\left({ }^{\circ} \mathrm{C}\right)$ & 88.2 & 103.3 \\
& $2.22\left(190^{\circ} \mathrm{C}\right)$ & $4.85\left(190^{\circ} \mathrm{C}\right)$ \\
MFR $(\mathrm{g} / 10 \mathrm{~min})$ & $4.99\left(215^{\circ} \mathrm{C}\right)$ & $13.46\left(255^{\circ} \mathrm{C}\right)$ \\
& $7.45\left(235^{\circ} \mathrm{C}\right)$ & $17.78\left(275^{\circ} \mathrm{C}\right)$
\end{tabular}


For the numerical simulation of the injection molding process similar or the same polymers must be used to have valid comparison with the experiments. Therefore, after reviewing the material database of Moldflow and Moldex3D for the polymers used in this study (LDPE and HDPE), the material parameters were selected from the Moldflow Plastics Labs database [32] based on the polymer family and trade name, melt flow index, and melting and transition temperatures. Table 2 shows the parameters for the Cross-WLF viscosity model, while Table 3 and Table 4 show the parameters for the modified Tait equation. It should be noted that Moldflow simulations are most available in literature $[1,2,8,11,14-$ $16,25,27,28,33-39]$. The heat capacity and thermal conductivity were assumed to be constant. For the LDPE, the heat capacity was $3400 \mathrm{~J} /(\mathrm{kg} \cdot \mathrm{K})$ and the thermal conductivity was $0.31 \mathrm{~W} /(\mathrm{m} \cdot \mathrm{K})$, while for the HDPE, the heat capacity and thermal conductivity were $2822 \mathrm{~J} /(\mathrm{kg} \cdot \mathrm{K})$ and $0.263 \mathrm{~W} /(\mathrm{m} \cdot \mathrm{K})$, respectively [32].

The processing parameters, such as melt temperature, mold temperature, injection pressure, and mold cavity thickness, and their levels are given in Table 4. In order to reduce the number of simulation trials (runs), a $\mathrm{L}_{27}\left(3^{4}\right)$ orthogonal array (OA) was used for the design of the simulation experiments [39, 40], as shown in Table 5.

Table 2. Cross-WLF model parameters for the LDPE and the HDPE [32]

\begin{tabular}{cccccccc}
\hline Constants & $\mathbf{n}$ & $\tau *(\mathbf{P a})$ & $\mathbf{D}_{\mathbf{1}}(\mathbf{P a} \mathbf{~ s})$ & $\mathbf{D}_{\mathbf{2}}(\mathbf{K})$ & $\mathbf{D}_{\mathbf{3}}(\mathbf{K} / \mathbf{P a})$ & $\mathbf{A}_{\mathbf{1}}$ & $\tilde{A}_{2}(\mathbf{K})$ \\
\hline LDPE & 0.366 & 55764 & $1.33 \times 10^{19}$ & 233.15 & 0 & 45.04 & 51.6 \\
HDPE & 0.163 & 273170 & $1.35 \times 10^{15}$ & 153.15 & 0 & 33.21 & 51.6 \\
\hline
\end{tabular}

Table 3. pVT model parameters for the LDPE [32]

\begin{tabular}{|c|c|c|c|c|c|}
\hline Constants & Values & Constants & Values & Constants & Values \\
\hline $\mathrm{b}_{1 \mathrm{~m}}\left(\mathrm{~m}^{3} / \mathrm{kg}\right)$ & $1.260 \times 10^{-3}$ & $\mathrm{~b}_{1 \mathrm{~s}}\left(\mathrm{~m}^{3} / \mathrm{kg}\right)$ & $1.106 \times 10^{-3}$ & $\mathrm{~b}_{5}(\mathrm{~K})$ & 390.65 \\
\hline $\mathrm{b}_{2 \mathrm{~m}}\left(\mathrm{~m}^{3} / \mathrm{kg} \mathrm{K}\right)$ & $9.690 \times 10^{-7}$ & $\mathrm{~b}_{2 \mathrm{~s}}\left(\mathrm{~m}^{3} / \mathrm{kg} \mathrm{K}\right)$ & $5.480 \times 10^{-7}$ & $\mathrm{~b}_{6}(\mathrm{~K} / \mathrm{Pa})$ & $1.870 \times 10^{-7}$ \\
\hline $\mathrm{b}_{3 \mathrm{~m}}(\mathrm{~Pa})$ & $1.002 \times 10^{8}$ & $\mathrm{~b}_{3 \mathrm{~s}}(\mathrm{~Pa})$ & $2.304 \times 10^{8}$ & $\mathrm{~b}_{7}\left(\mathrm{~m}^{3} / \mathrm{kg}\right)$ & $0.155 \times 10^{-3}$ \\
\hline $\mathrm{b}_{4 \mathrm{~m}}(1 / \mathrm{K})$ & $4.471 \times 10^{-3}$ & $\mathrm{~b}_{4 \mathrm{~s}}(1 / \mathrm{K})$ & $4.060 \times 10^{-3}$ & $\begin{array}{l}\mathrm{b}_{8}(1 / \mathrm{K}) \\
\mathrm{b}_{9}(1 / \mathrm{Pa})\end{array}$ & $\begin{array}{c}0.103 \\
3.380 \times 10^{-8}\end{array}$ \\
\hline
\end{tabular}

Table 4. pVT model parameters for the HDPE [32]

\begin{tabular}{|c|c|c|c|c|c|}
\hline Constants & Values & Constants & Values & Constants & Values \\
\hline $\mathrm{b}_{1 \mathrm{~m}}\left(\mathrm{~m}^{3} / \mathrm{kg}\right)$ & $1.274 \times 10^{-3}$ & $\mathrm{~b}_{1 \mathrm{~s}}\left(\mathrm{~m}^{3} / \mathrm{kg}\right)$ & $1.075 \times 10^{-3}$ & $\mathrm{~b}_{5}(\mathrm{~K})$ & 414.50 \\
\hline $\mathrm{b}_{2 \mathrm{~m}}\left(\mathrm{~m}^{3} / \mathrm{kg} \mathrm{K}\right)$ & $1.026 \times 10^{-6}$ & $\mathrm{~b}_{2 \mathrm{~s}}\left(\mathrm{~m}^{3} / \mathrm{kg} \mathrm{K}\right)$ & $2.077 \times 10^{-7}$ & $\mathrm{~b}_{6}(\mathrm{~K} / \mathrm{Pa})$ & $1.543 \times 10^{-7}$ \\
\hline $\mathrm{b}_{3 \mathrm{~m}}(\mathrm{~Pa})$ & $9.263 \times 10^{7}$ & $\mathrm{~b}_{3 \mathrm{~s}}(\mathrm{~Pa})$ & $3.324 \times 10^{8}$ & $\mathrm{~b}_{7}\left(\mathrm{~m}^{3} / \mathrm{kg}\right)$ & $0.187 \times 10^{-3}$ \\
\hline $\mathrm{b}_{4 \mathrm{~m}}(1 / \mathrm{K})$ & $4.941 \times 10^{-3}$ & $\mathrm{~b}_{4 \mathrm{~s}}(1 / \mathrm{K})$ & $2.460 \times 10^{-6}$ & $\begin{array}{l}\mathrm{b}_{8}(1 / \mathrm{K}) \\
\mathrm{b}_{9}(1 / \mathrm{Pa})\end{array}$ & $\begin{array}{c}0.052 \\
1.023 \times 10^{-8} \\
\end{array}$ \\
\hline
\end{tabular}

\subsection{Part geometry and design of experiments}

The molded part is a spiral $4 \mathrm{~mm}$ wide and $2000 \mathrm{~mm}$ long, as shown in Figure 1. Three different thicknesses, i.e., 1.0, 1.5 and $2.0 \mathrm{~mm}$, were considered to achieve a wide range of shear rates. Due to its flow length, this mold is considered an open mold. The mold is filled by means of a constant flow rate and the filling stage ends when the programmed injection pressure is reached because the injection machine does not have enough pressure to fill the mold cavity completely. 


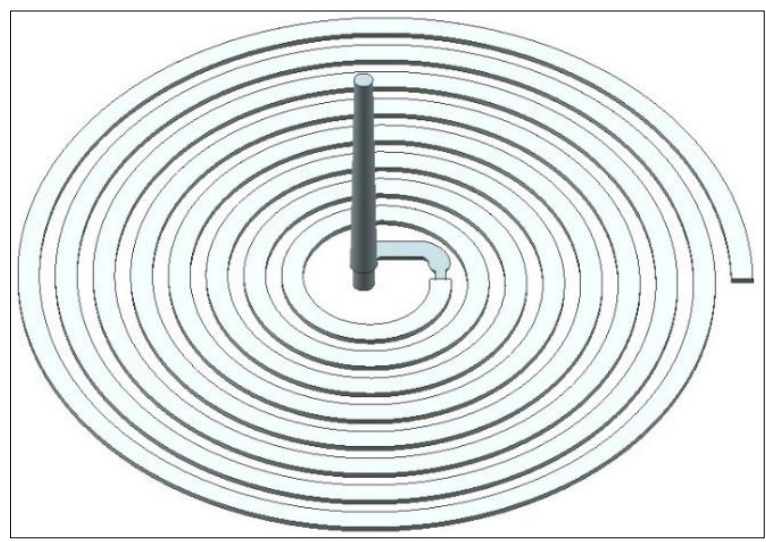

Figure 1. Solid model for the spiral part and the runner system

The processing parameters, such as melt temperature, mold temperature, injection pressure, and mold cavity thickness, and their levels are given in Table 5. In order to reduce the number of simulation trials (runs), a $\mathrm{L}_{27}\left(3^{4}\right)$ orthogonal array (OA) was used for the design of the simulation experiments [40, 41], as shown in Table 6.

Table 5. Process variables and their levels

\begin{tabular}{ccccc}
\hline Parameter/Polymer & & \multicolumn{3}{c}{ Level } \\
\cline { 3 - 5 } HDPE/LDPE & & 1 & 2 & 3 \\
\hline Melt temperature $\left({ }^{\circ} \mathrm{C}\right)$ & $\mathrm{A}$ & $255 / 215$ & $275 / 235$ & $295 / 255$ \\
Spiral thickness $(\mathrm{mm})$ & $\mathrm{B}$ & 1.0 & 1.5 & 2.0 \\
Injection pressure $(\mathrm{MPa})$ & $\mathrm{C}$ & 70 & 110 & 140 \\
Mold temperature $\left({ }^{\circ} \mathrm{C}\right)$ & $\mathrm{D}$ & 30 & 40 & 50 \\
\hline
\end{tabular}

\subsection{Simulation of the injection molding process}

The polymer flow through the spiral part was simulated by Moldflow and Moldex3D software, imposing the same injection molding conditions. The $\mathrm{L}_{27} \mathrm{OA}$ (Table 6) was randomly run by each simulation program. It should be noted that runs 3, 8, 12, 17, 21 and 25 were used for testing the ANN model.

The spiral part was modeled by the NX7 software, imported to Moldflow and Moldex3D programs, and then meshed.

For Moldflow simulation, the cold runner system was created in the preprocessor and meshed with beam elements. For Moldex3D simulation, the runner system was also created in the NX7 software and meshed together with the part using the same type of elements, i.e., tetrahedral elements.

Simulations on a basis of surface mesh (2.5D analysis) and volume mesh (3D) were performed under non-isothermal conditions and the filling simulation results were compared in order to acquire the best results.

For Moldex3D, the simulation results derived from 2.5D and 3D simulations were nearly identical and comparable to those in the real molding experiments ( $p$-value $>0.05$ and the relative error between $2.5 \mathrm{D}$ and $3 \mathrm{D}$ results $<5 \%$ ).

For Moldflow, both 2.5D and 3D simulation results deviated from those of the real molding experiments, and surprisingly, the 3D simulation results deviated much from the $2.5 \mathrm{D}$ simulation results. Thus, in the case of Moldflow, for the analysis of the flow length, a 2.5D model with 12 layers across the thickness was considered. After preliminary simulations, the best meshing strategy was identified for both simulation programs and kept constant for the further simulation runs. The number of elements in the Moldflow mesh was 54,024 for the part and 77 for the cold runner, compared to that in the Moldex3D mesh, of 444,746 for the part and 32,438 for the runner. 
The flow fronts from simulations were imported into the CAD software and measured using line and arc construction tools.

Table 6. Layout of the $\mathrm{L}_{27} \mathrm{OA}$

\begin{tabular}{|c|c|c|c|c|}
\hline \multirow{2}{*}{ DOE } & \multicolumn{4}{|c|}{ Factors } \\
\hline & $\mathrm{A}$ & B & $\mathrm{C}$ & D \\
\hline 1 & 1 & 1 & 1 & 1 \\
\hline 2 & 1 & 1 & 2 & 2 \\
\hline $3 *$ & 1 & 1 & 3 & 3 \\
\hline 4 & 1 & 2 & 1 & 2 \\
\hline 5 & 1 & 2 & 2 & 3 \\
\hline 6 & 1 & 2 & 3 & 1 \\
\hline 7 & 1 & 3 & 1 & 3 \\
\hline $8^{*}$ & 1 & 3 & 2 & 1 \\
\hline 9 & 1 & 3 & 3 & 2 \\
\hline 10 & 2 & 3 & 1 & 1 \\
\hline 11 & 2 & 3 & 2 & 2 \\
\hline $12 *$ & 2 & 3 & 3 & 3 \\
\hline 13 & 2 & 1 & 1 & 2 \\
\hline 14 & 2 & 1 & 2 & 3 \\
\hline 15 & 2 & 1 & 3 & 1 \\
\hline 16 & 2 & 2 & 1 & 3 \\
\hline $17 *$ & 2 & 2 & 2 & 1 \\
\hline 18 & 2 & 2 & 3 & 2 \\
\hline 19 & 3 & 2 & 1 & 1 \\
\hline 20 & 3 & 2 & 2 & 2 \\
\hline $21 *$ & 3 & 2 & 3 & 3 \\
\hline 22 & 3 & 3 & 1 & 2 \\
\hline 23 & 3 & 3 & 2 & 3 \\
\hline 24 & 3 & 3 & 3 & 1 \\
\hline $25 *$ & 3 & 1 & 1 & 3 \\
\hline 26 & 3 & 1 & 2 & 1 \\
\hline 27 & 3 & 1 & 3 & 2 \\
\hline
\end{tabular}

The most accurate simulations were those closer to the experimental results. The error-estimate is defined as follows [40, 41]:

$$
R E=\frac{l_{\text {sim }}-l_{\text {exp }}}{l_{\text {exp }}} \times 100
$$

in which $l_{\exp }$ and $l_{\text {sim }}$ is the experimental and simulation/prediction value of the flow length, respectively.

\subsection{Injection molding experiments}

Injection molding experiments were carried out based on the $\mathrm{L}_{27} \mathrm{OA}$ (Table 6) using an ARBURG injection molding machine (Allrounder $320 \mathrm{C}$ Golden Edition, Germany) with a clamping force of 500 $\mathrm{kN}$. All the other processing parameters were kept constant. The holding pressure was set to $63 \mathrm{MPa}$. The holding and cooling times were set to 7.5 and 15 seconds, respectively. 


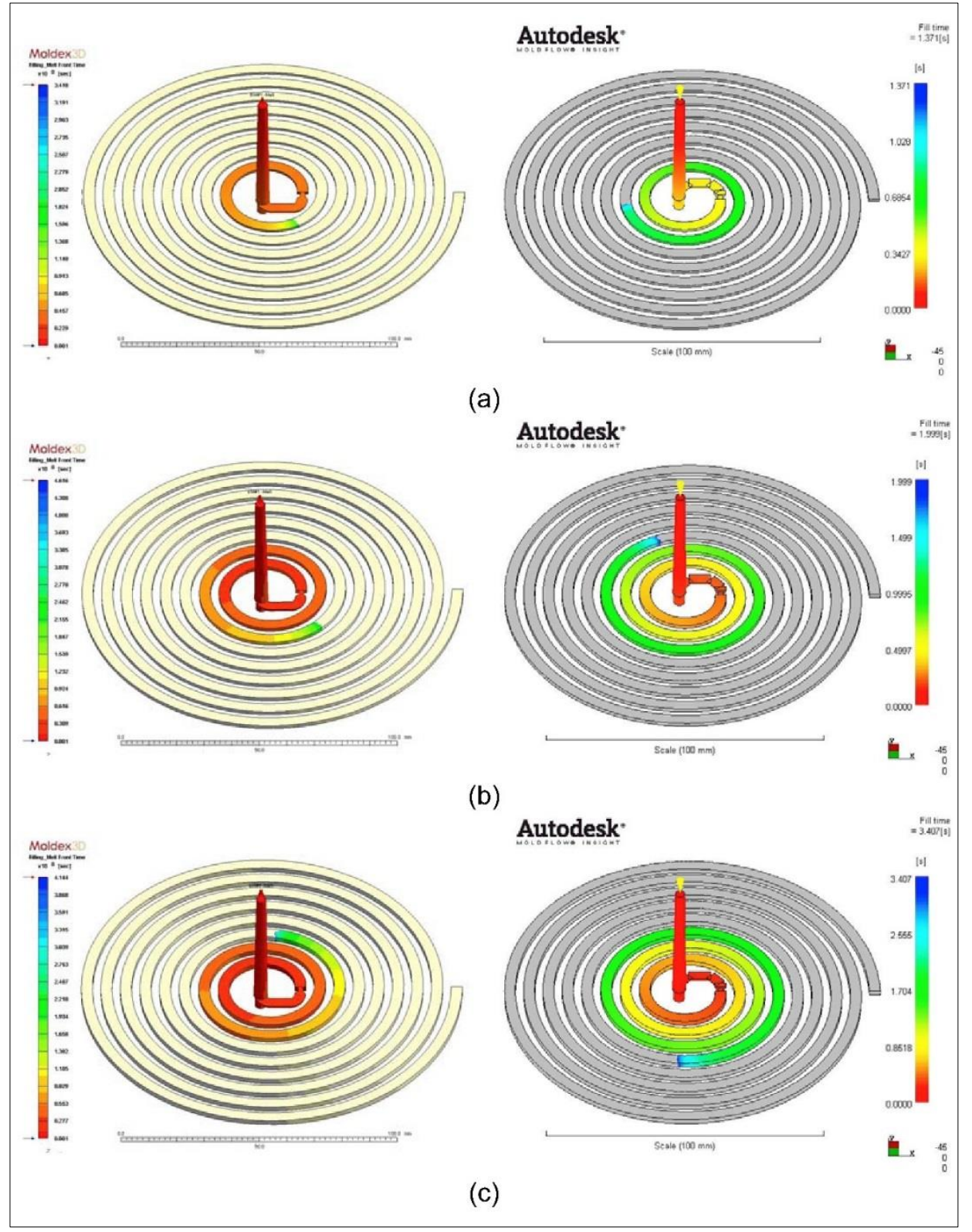

Figure 2. LDPE melt flow length - comparison between Moldex3D (left column) and moldflow (right column) simulations: (a) DOE 3 (1.0 mm cavity thickness);

(b) DOE 21 (1.5 mm cavity thickness); (c) DOE 12 (2.0 mm cavity thickness)

In the experiments, the mold temperature was controlled by a thermal regulator (Termotech Plus, Dega, Italy), with a heating capacity of $6 \mathrm{~kW}$ and a maximum oil temperature of $200^{\circ} \mathrm{C}$.

For each set of processing conditions in Table 6 , the first 10 moldings were discarded before collecting at least 25 moldings, from which 10 moldings were randomly selected for measuring the flow length and part weight. Since LDPE and HDPE are semi-crystalline polymers, the molded parts were allowed to relax for at least 24 hours before measurements were taken. 


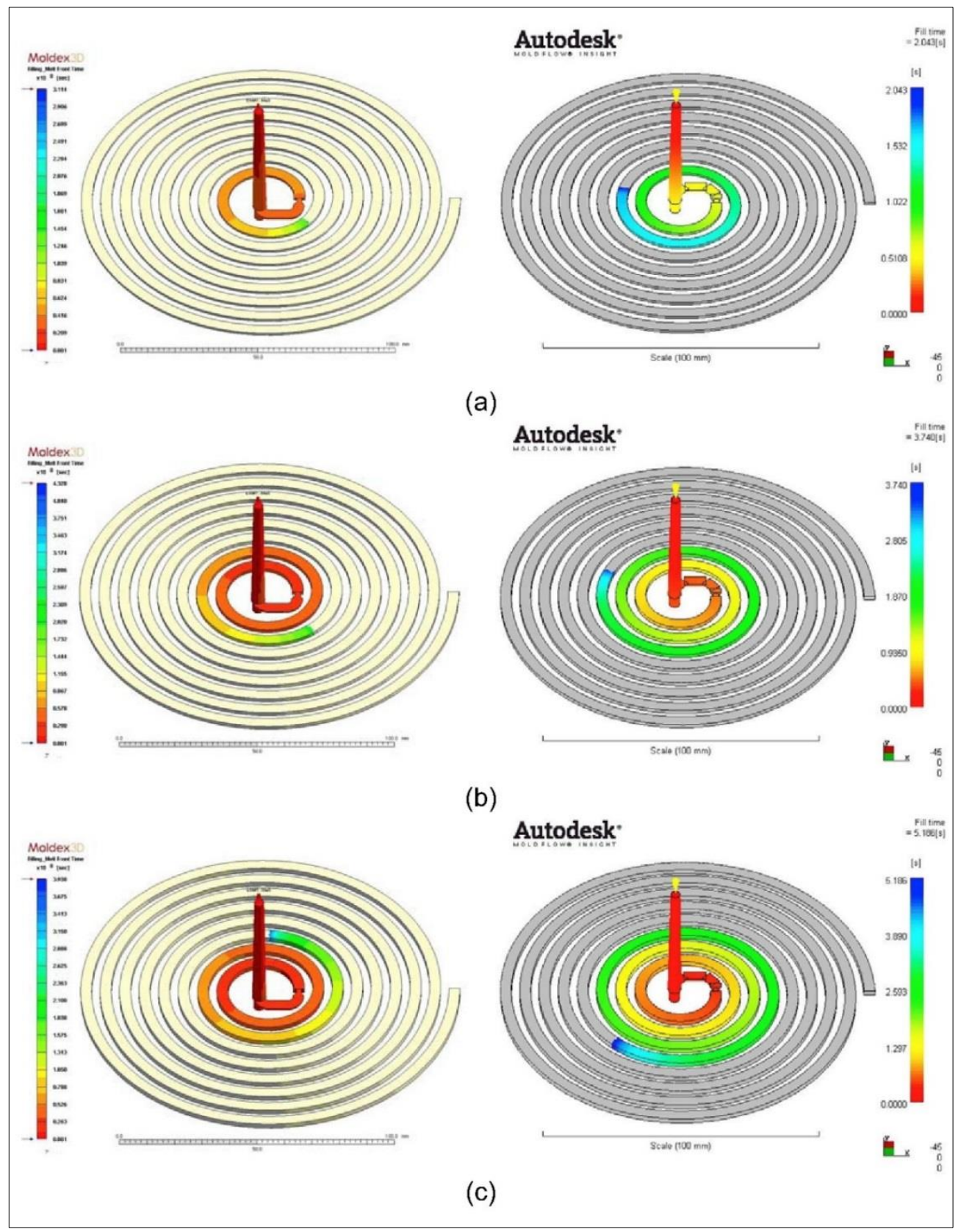

Figure 3. HDPE melt flow length - comparison between Moldex3D (left column) and Moldflow (right column) simulations: (a) DOE 3 (1.0 mm cavity thickness);

(b) DOE 21 (1.5 mm cavity thickness); (c) DOE 12 (2.0 mm cavity thickness)

The reproducibility of the injection molding process was assessed through part weighing. In general, it was observed that more than $95 \%$ of the moldings were inside the statistic control limits for all processing conditions [41].

\section{Results and discussions}

Figure 2 and Figure 3 show the flow length (filling distance into the mold cavity) with respect to different injection molding conditions as predicted by Moldex3D and Moldflow, for LDPE and HDPE, respectively. As shown in these figures, the filling distance increases rapidly with the increase of the cavity thickness. Under the same injection molding conditions, the flow front in Moldflow advances faster and, thus, farther than in the Moldex3D, as shown in Figure 2 and Figure 3. 
Since the viscosity and $p V T$ models are the same, the discrepancy in the flow length is most likely due to the differences in geometry modeling and meshing as well as in the simulation assumptions. For example, Moldex3D simulates the melt elastic behavior in addition to its viscous behavior during processing.

On the contrary, the Moldflow assumes that the material becomes suddenly elastic when the temperature falls below the transition temperature, at which the melt stops to flow.

Figure 4 and Figure 5 show the comparison of the Moldflow predicted and experimental (images of the actual injection molded parts) flow lengths, under different injection molding conditions, i.e., the worst (DOE 9 for LDPE and DOE 12 for HDPE) and best (DOE 1 for both LDPE and HDPE polymers) case predictions. It was found that the flow length predicted by the Moldflow is longer than the experimentally measured value.

As the cavity thickness increases, the deviations between experimental and simulation results increase, as shown in Figure 4 and Figure 5. For HDPE, the maximum relative error between experimental and Moldflow simulations is $92.6 \%$, while the minimum is $6.8 \%$.

For LDPE, the maximum relative error between experimental and Moldflow simulations is $115 \%$, while the minimum is $21.6 \%$. However, the MRE of all 27 runs is $41.2 \%$ for HDPE and $51.5 \%$ for LDPE and therefore the Moldflow flow length simulations will be of low quality.

Although not perfectly superposed, the Moldex3D simulation results are consistent with the experimental data, with only marginal differences between simulation and experiments ( $p$-value >0.05).

The LDPE and HDPE melt flow lengths as predicted by Moldex3D are compared with the corresponding experimental values in Figure 6 and Figure 7, the worst (DOE 3 for LDPE and DOE 2 for HDPE) and best (DOE 19 for LDPE, and DOE 22 for HDPE) case predictions.

For HDPE, the maximum error between experiments and Moldex3D simulations is $28 \%$, while the minimum is $0.2 \%$. For LDPE, the maximum error between experiments and Moldex $3 \mathrm{D}$ simulations is $31 \%$, while the minimum is $0.2 \%$. However, the MRE of all 27 runs is $8.3 \%$ for HDPE and $14.4 \%$ for LDPE and therefore the Moldex3D predicts accurate results.

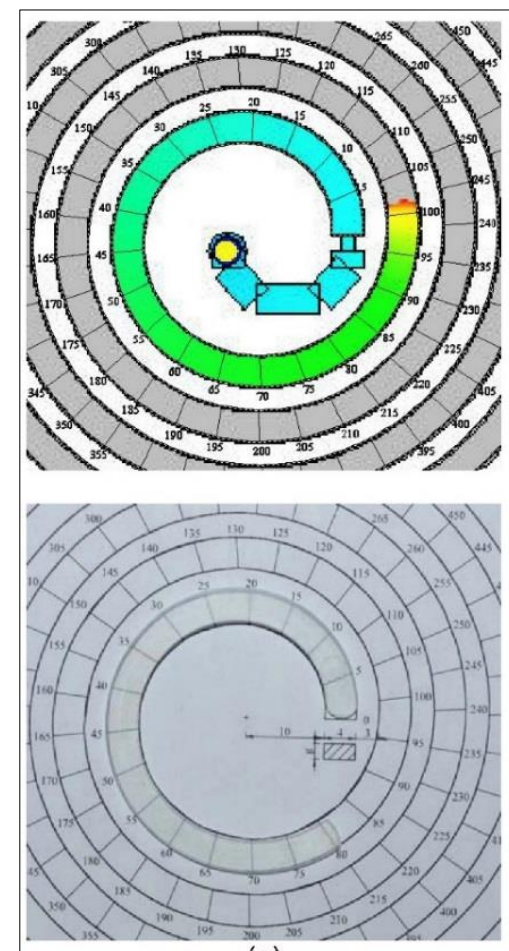

(a)

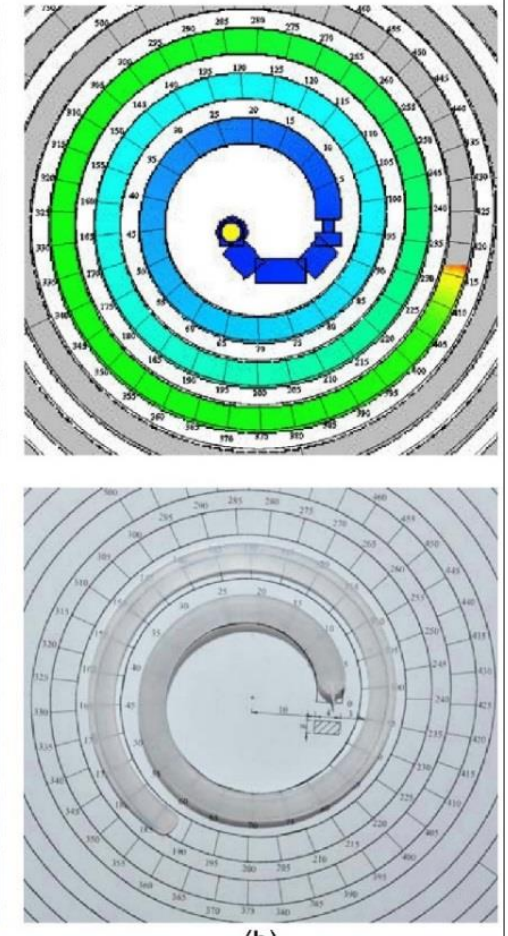

(b)

Figure 4. Comparison between Moldflow and experimental LDPE flow lengths for cavity thickness of (a) $1.0 \mathrm{~mm}$ (DOE 1, best prediction, relative error of $21.6 \%$ ) and (b) $2.0 \mathrm{~mm}$ (DOE 9, worst prediction, relative error of $115 \%$ ) 
The deviations between numerical simulation and experiment can be attributed to the fact that, except for the thermal and mechanical properties, the material properties, such as viscosity model, pVT properties, heat transfer coefficient, were obtained from the database [32], and may be different from the real ones.

Moreover, the pressure-dependence of viscosity is not taken into account in the simulation $\left(D_{3}=0\right.$, Table 1), although this effect becomes important when high pressures are encountered as in the case of mold filling and packing phases, especially for the LDPE. HDPE is known to be less sensitive to temperature and pressure compared to LDPE. However, HDPE has high viscosity due to its molecular weight.

The sprue channel may also have an influence on the flow length especially for the Moldex3D simulations. Due to the cone shape profile, both shear and normal stresses are developed along the sprue wall and, therefore, viscosity increases about three times more than shear viscosity [28]. The rise of viscosity in the sprue channel would decrease the flow length.

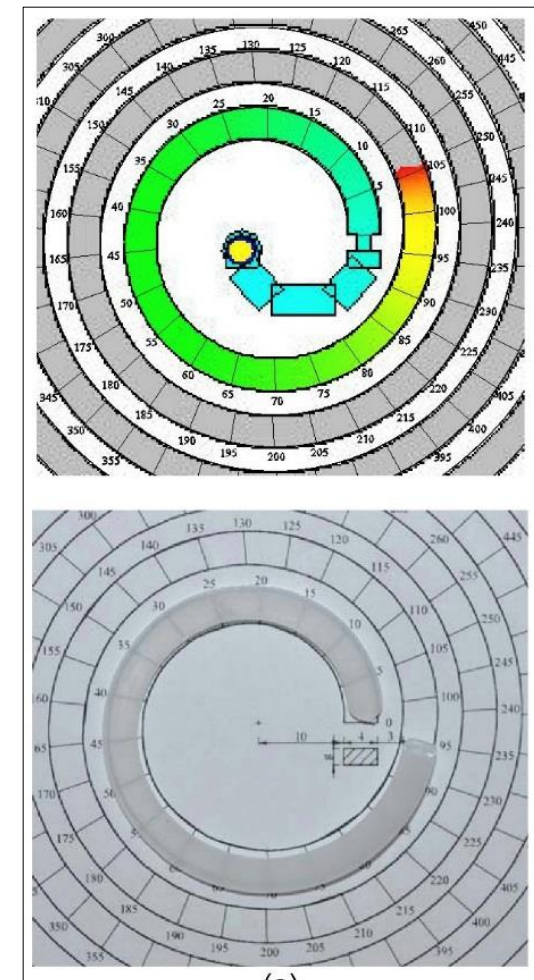

(a)

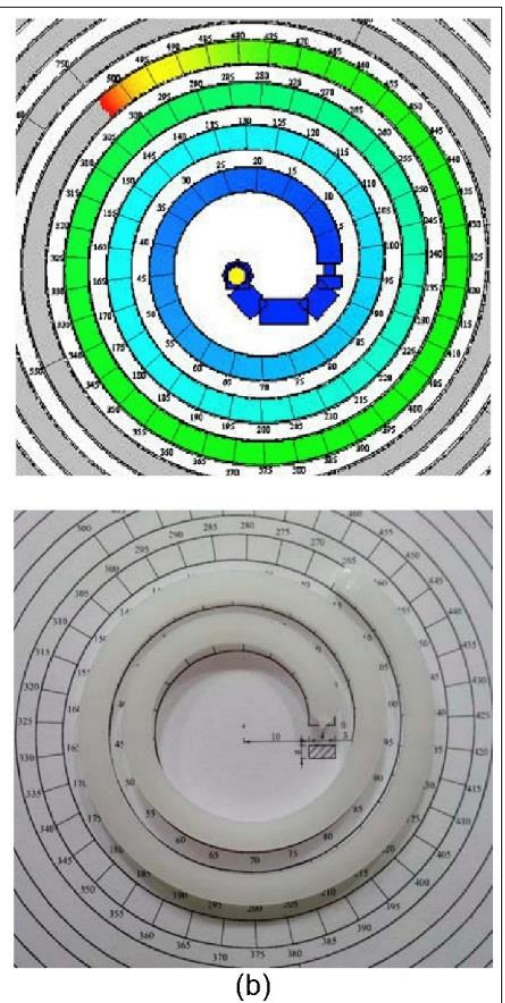

(b)

Figure 5. Comparison between Moldflow and experimental HDPE flow lengths for cavity thickness of (a) $1 \mathrm{~mm}$ (DOE 1, best prediction, relative error of $6.8 \%$ ) and (b) $2 \mathrm{~mm}$ (DOE 12, worst prediction, relative error of $92.6 \%$ )

The heat transfer coefficient is also an important parameter, especially for thin-wall parts. If the heat transfer coefficient is too high, the melt flow length in simulation will be shorter than its experimental value. However, if the heat transfer coefficient is too low, the melt flow length in simulation will be greater than its experimental value.

Figure 8 shows the comparison between the simulation and experimental flow lengths for all conditions considered in Table 5. 


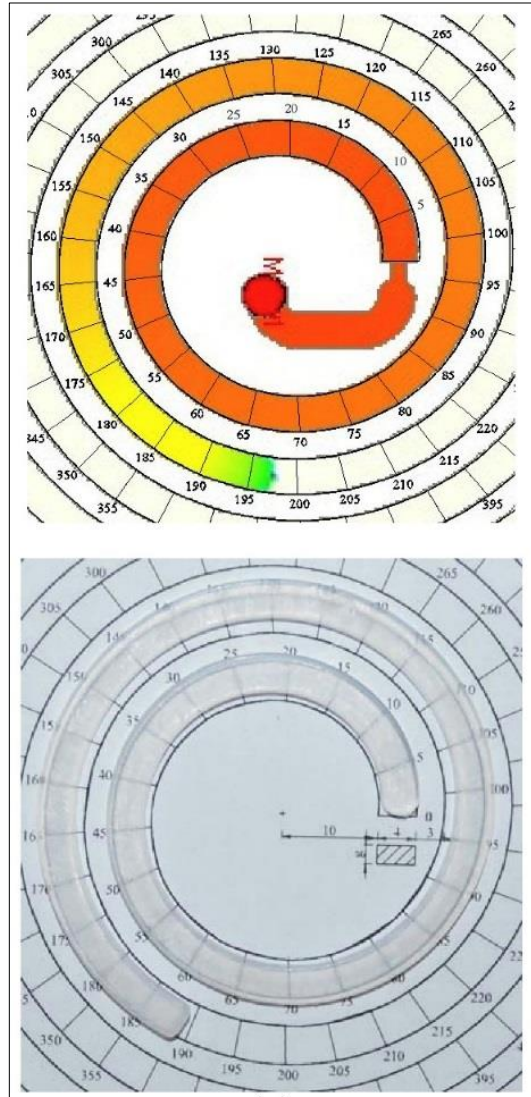

(a)

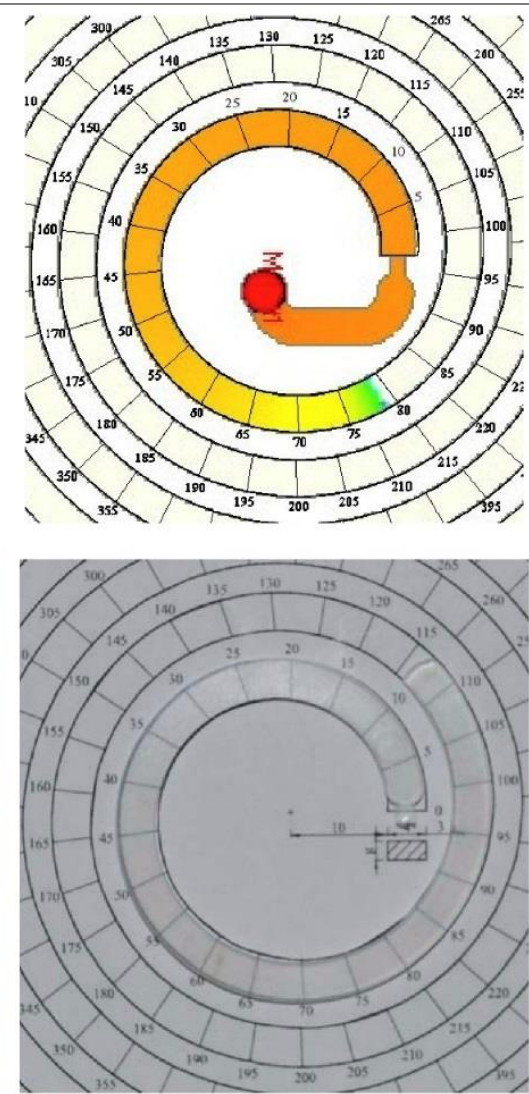

(b)

Figure 6. Comparison between Moldex3D and experimental LDPE

flow lengths for cavity thickness of (a) $1.5 \mathrm{~mm}$ (DOE 19, best prediction, relative error of $0.19 \%$ ) and (b) $1 \mathrm{~mm}$ (DOE 3, worst prediction, relative error of $31 \%$ )

The simulation results show the same trend as compared to the experimental ones. However, the flow lengths predicted by the Moldflow are greater than those predicted by the Moldex $3 \mathrm{D}$ or their corresponding experimental values.

The Moldflow over predicts the flow length, especially for cavities with higher thickness (DOE 7 to DOE 12, and DOE 22 to DOE 24).

On the other hand, although they do not perfectly reproduce the experimental data, the Moldex3D simulation results agree well with the experimental results. 


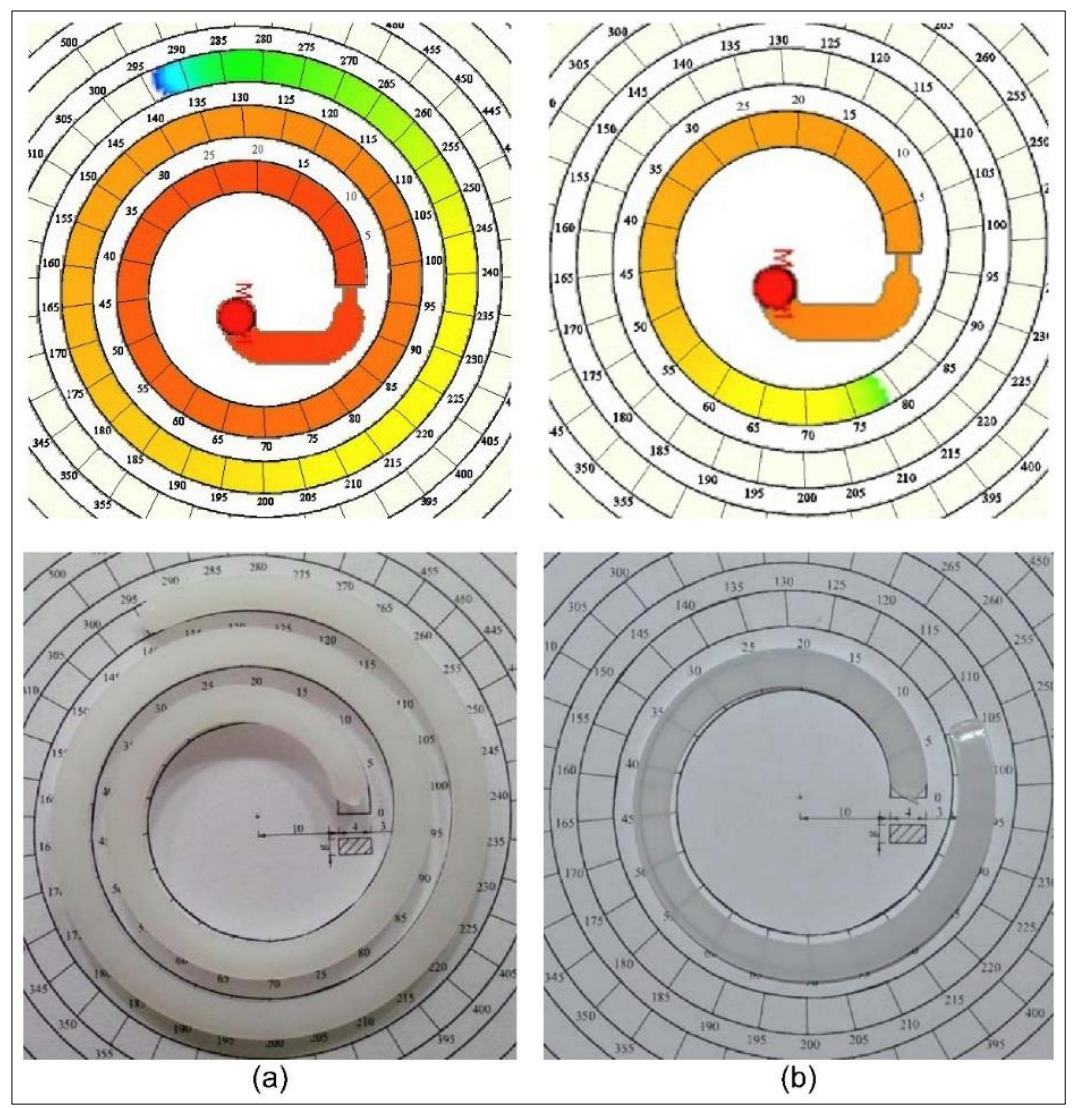

Figure 7. Comparison between Moldex3D and experimental HDPE

flow lengths for cavity thickness of (a) $2.0 \mathrm{~mm}$ (DOE 22, best prediction,

relative error of $0.2 \%$ ) and (b) $1.0 \mathrm{~mm}$ (DOE 2, worst prediction, relative error of $28 \%$ )

The one-way analysis of variance (ANOVA) and the $t$-test were used for checking the significance of differences at a level of significance of 0.05 ( $p<0.05$ indicates statistically significant differences) [41].

First, the difference between the Moldex3D, Moldflow and experimental flow lengths was investigated by using the ANOVA, considering the flow length for all 27 runs. The $p$-value lower than the significance level ( $p=0.0004$ and $F=8.75>F_{\text {crit }}=3.11$ for HDPE and 0.0002 and $F=9.84>F_{\text {crit }}=3.11$ for LDPE) suggests that the Moldex3D, Moldflow and the experiment do not perform equally. Specifically, Moldex3D (mean (standard deviation), 181.93 (73.65) $\mathrm{mm}$ for HDPE and 177.63 (77.01) $\mathrm{mm}$ for LDPE) performed better than Moldflow (mean (standard deviation), 274.26 (118.71) $\mathrm{mm}$ for HDPE and 269.78 (112.02) $\mathrm{mm}$ for LDPE) in terms of flow length, if compared with the experiment (mean (standard deviation), 189.13 (63.13) $\mathrm{mm}$ for HDPE and 178.59 (61) $\mathrm{mm}$ for LDPE). 


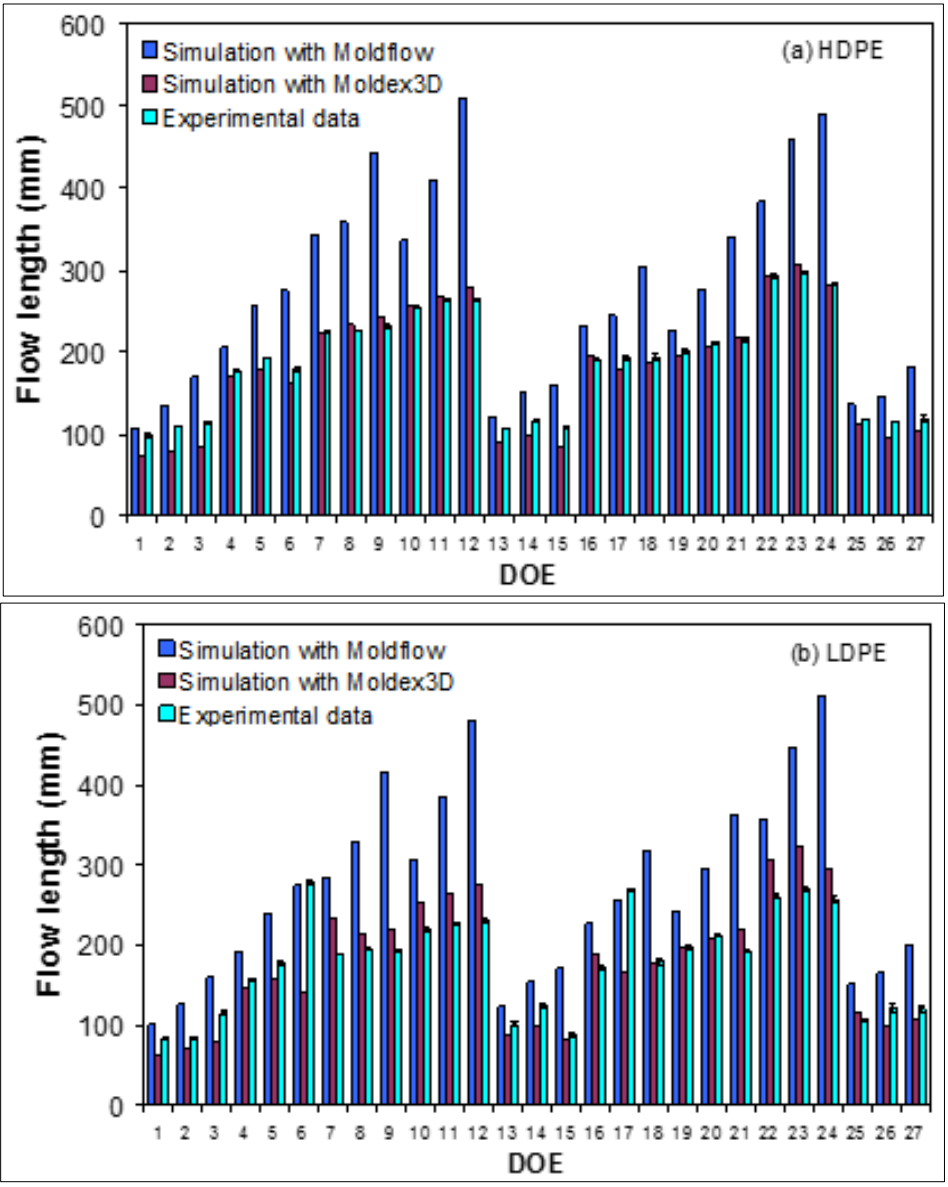

Figure 8. Comparison between simulation and experimental flow lengths
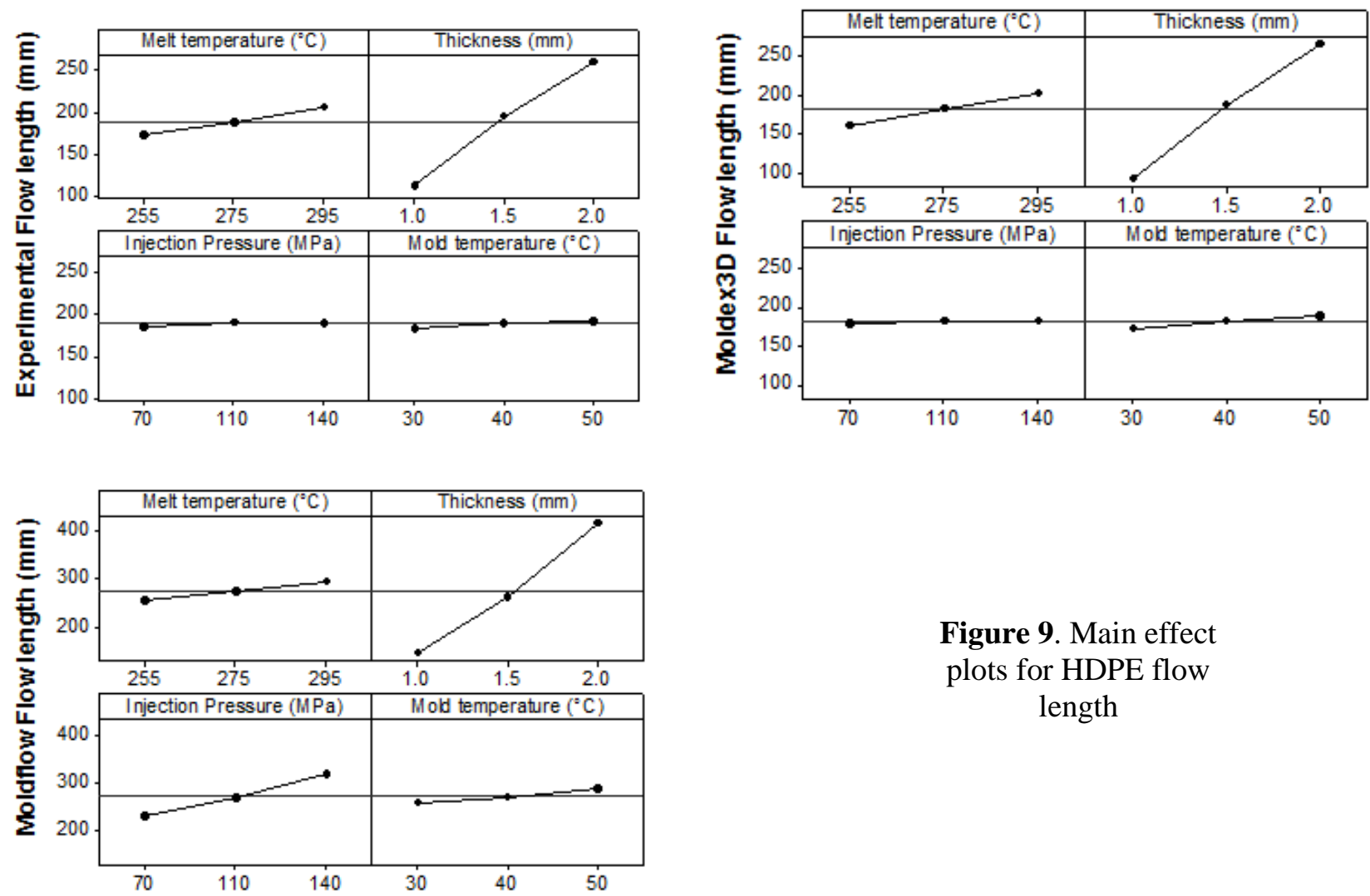

Figure 9. Main effect plots for HDPE flow length 

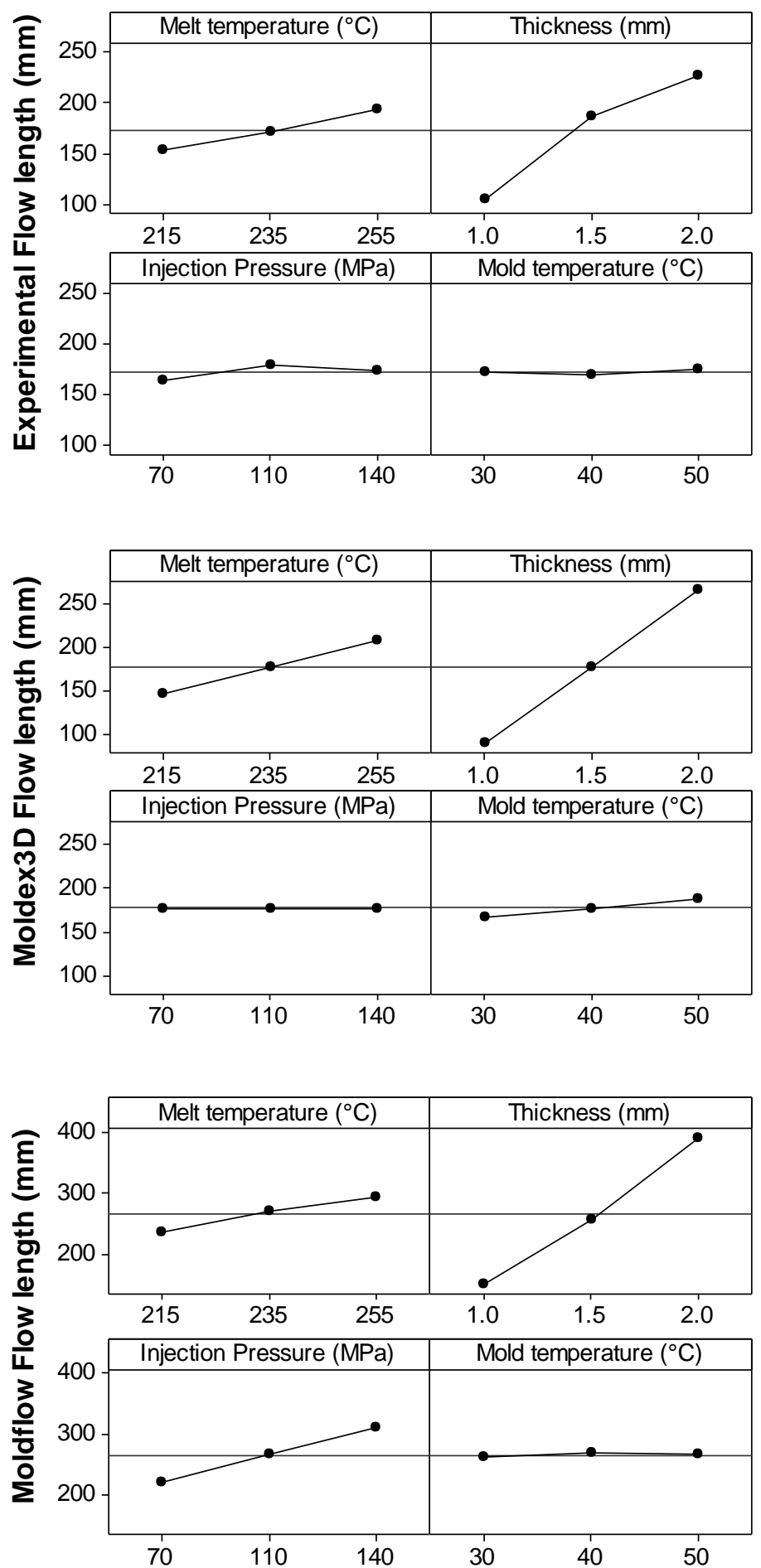

Figure 10. Main effect plots for LDPE flow length

Based on the $t$-test we have found that there is no statistically significant difference between the Moldex3D and the experimental flow lengths ( $p$-value is equal to 0.35 for HDPE and 0.48 for LDPE). However, when comparing the Moldflow and the experimental data, the $p$-value is 0.0003 for LDPE and 0.001 for HDPE, which indicates that the difference between the Moldflow and experimental flow lengths is statistically significant. Furthermore, when comparing the Moldex3D and Moldflow results, the $t$-test with $p$-value of 0.001 for both HDPE and LDPE suggests that the difference between 
Moldex3D and Moldflow flow lengths is statistically significant. The flow lengths predicted by Moldflow were significantly greater compared to the experimental values (mean, 274.26 mm for HDPE vs. $189.13 \mathrm{~mm}$ for HDPE).

To investigate systematically the effect of processing parameters on the flow length, the main effect plots were constructed, as shown in Figure 9 and Figure 10, for LDPE and HDPE, respectively. The interactions between the different factors were also analyzed. It was found that, out of the four processing parameters, part thickness and melt temperature are decisive parameters, while mold temperature and injection pressure are secondary parameters.

In the simulation under the Moldflow environment, three parameters were found to be statistically significant ( $p$-value smaller than 0.05): part thickness, melt temperature, and injection pressure. The flow length predicted by Moldflow increases with increasing melt temperature, part thickness and injection pressure, as shown in Figure 9 and Figure 10.

The flow length predicted by Moldex3D increases with increasing part thickness, melt temperature and mold temperature. However, the flow length predicted by Moldex3D appeared less dependent on injection pressure.

The experimental flow length increases with increasing part thickness, melt temperature and injection pressure. The mold temperature becomes an important parameter in terms of flow length if correlated with part thickness due to the effect of the frozen layer.

Concerning the interaction effects, only one statistically significant interaction ( $p$-value smaller than 0.05) was identified both for simulation and experimental analyses, the interaction between melt temperature and part thickness.

Increasing thickness from low to high level results in almost doubling the flow length, as shown in Figure 9 and Figure 10. This factor becomes more significant as the melt and mold temperatures increase. At higher melt temperatures, the viscosity of the polymer melt decreases and the polymer flows easier into the mold and, as a result, the flow length increases. Moreover, a higher melt temperature delays the solidification of the melt and the polymer has longer time to stay molten (the polymer cools slower), especially at thicker walls, and thus travel longer, resulting in greater length.

In the case of smaller thickness, the cross-section area, which contributes to the filling of the cavity, is reduced and, consequently, the flow front advancement is slowed down. This effect is more important in the case of lower melt and mold temperatures, as shown in Figure 8 and Figure 9. The polymer injected first solidifies as it comes into contact with the cold mold wall. The solidified skin polymer acts as a second wall inside the mold cavity narrowing the flow channel (creating a smaller cross-section), resulting in a shorter flow length. On the contrary, the mold cavity with a thicker section offers a significant lower flow resistance than that with a thin section, resulting in a greater flow length.

Another important aspect is shear heating, which also contributes to an additional rise in melt temperature during the mold filling of the thin spiral and positively impacts on melt viscosity, so the polymer melt will flow easier.

\subsection{Architecture and training of the ANN model}

A three-layer ANN model with a sigmoid transfer function with back-propagation algorithm between the input and the hidden layer and a linear transfer function between the hidden and the output layer was used in this study [5, 20, 22, 23, 42, 43]. The architecture of the ANN model used to predict the flow length is shown in Figure 11. 


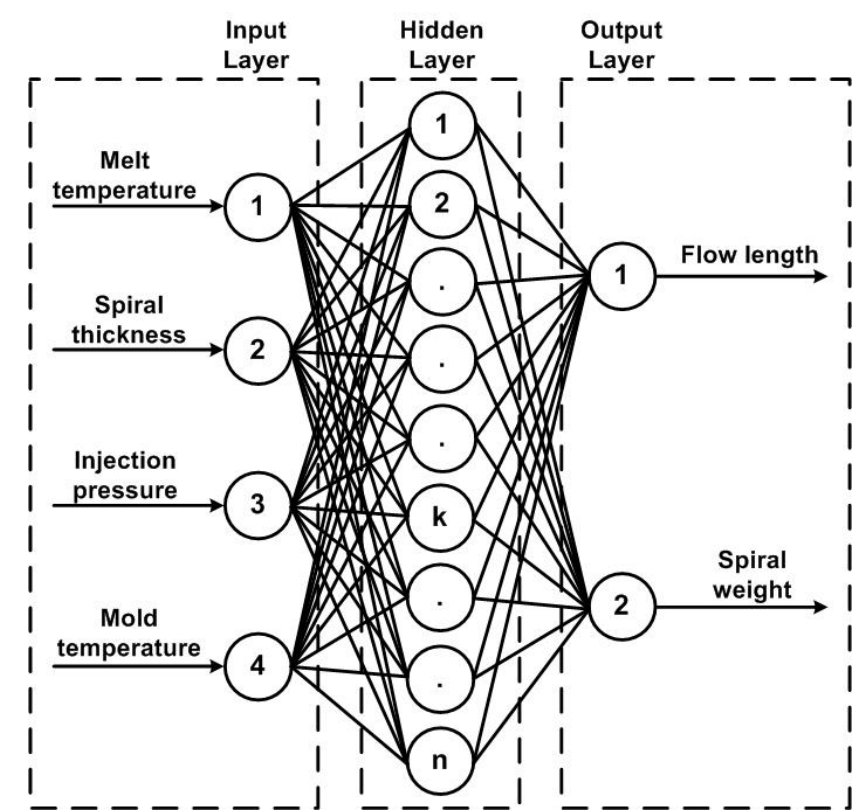

Figure 11. Architectures of the AN $\bar{N}$ for flow length

The input layer has four neurons corresponding to the design variables, such as melt temperature, spiral thickness, injection pressure, and mold temperature, whereas the output layer have two nodes, i.e., flow length and spiral weight.

The capability of the ANN model to predict the flow length is influenced by the number of neurons in the hidden layer of the network and the connection type. It was shown that increasing the number of neurons in the hidden layer increases the accuracy of the network up to a point, after which it declines, allowing the optimum number of neurons to be identified [5, 20, 22, 24]. The trial-and-error method was used to find the optimum number of neurons in the hidden layer, i.e., the mean square error (MSE) reached a minimum value. Seven and nine neurons were found to be optimum for the LDPE and HDPE hidden layer, respectively. Therefore, the optimum ANN configuration was 4-7-1 (4 neurons in the input layer, 7 in the hidden layer and 1 in the output layer) for LDPE and 4-9-1 (4 neurons in the input layer, 9 in the hidden layer and 1 in the output layer) for HDPE, respectively. To reach the prediction accuracy - the maximum error was set to $10 \%$, the number of training cycles was set to 18,000 for HDPE and 40,000 for LDPE.

Generally, the quality of the ANN model depends on the quality of the training datasets $[5,20,22$, 24]. In this study, two different scenarios, aimed at testing the capabilities of the artificial neural network to predict the flow length, were developed. The first scenario made use of experimentally measured flow lengths, while in the second scenario the flow lengths simulated by Moldex3D and Moldflow were considered. Considering the aforementioned scenarios, three datasets were generated for modeling with neural network, namely: a dataset generated from injection molding experiments and two datasets generated from Moldflow and Moldex3D simulations, respectively. An accurate ANN model requires a very large dataset and additional validation data [5, 20, 22, 24]. However, in this study, the training dataset includes a small number of data in order to reduce the computing time.

The datasets are 27 design points sampled by the Taguchi DOE technique, as shown in Table 5. The idea was to reduce the number of runs as much as possible in order to predict the flow length using the injection molding simulations or experiments. In this way, the network is trained over a wide range of values with a reduced number of data, but not over-trained.

Each dataset collected either from simulations or injection molding experiments was divided into a training dataset - used to train the neural network and adjust the weights of all connecting nodes until the desired error is reached, and a testing dataset - used to test the network performance. Out of the total of 27 data, 21 were considered for training and only 6 for testing the ANN model. Data were randomly selected from Table 5 (DOE 3, 8, 12, 17, 21 and 25, respectively). 
The training process was conducted in two scenarios. In the first scenario, the ANN model was trained with experimental data and the ANN predictions were compared with the experimental testing dataset. In the second scenario, the ANN model was trained with simulation data and the predicted values were compared with both experimental and simulation datasets.

For the discussion on the ANN models, the following abbreviations will be used throughout the paper: ANN-Moldex3D for the neural network trained with Moldex3D dataset, ANN-Moldflow for the neural network trained with Moldflow dataset, and ANN-Experiment for the neural network trained with experimental data. The quality of the ANN prediction (the agreement between the training and the prediction datasets) was assessed based on the correlation coefficient $(R)$, the mean relative error and the root mean square error defined by $[5,22,41]$ :

$$
\begin{aligned}
& M R E=\frac{1}{N} \sum_{i=1}^{N}\left|\frac{\tilde{l}_{i, \text { pred }}-l_{i, \text { exp } / \mathrm{sim}}}{l_{i, \text { pred }}}\right| \times 100 \\
& R M S E=\left[\frac{1}{N} \sum_{i=1}^{N}\left(\tilde{l}_{i, \text { pred }}-l_{i, \text { exp } / \mathrm{sim}}\right)^{2}\right]^{1 / 2}
\end{aligned}
$$

where $l_{i, \exp / \text { sim }}$ is the measured/simulation value, $\tilde{l}_{i, \text { pred }}$ is the ANN predicted value of $i$ th point, and $N$ is the number of test data.

The network showing the lowest MRE and RMSE, and the correlation coefficient closest to one was selected as the best-trained network.

For evaluating the training performance of the ANN models, a MRE of 5\% was taken as a limit for the model performance, while, for the testing performance of the ANN models, a MRE of $10 \%$ was considered.

The one-way analysis of variance (ANOVA) and the $t$-test were used for testing the significance of differences at a 0.05 level of significance ( $p<0.05$ indicates statistically significant differences) [41].

The network performance for the ANN-Experiment, ANN-Moldflow and ANN-Moldex3D is illustrated in Table 7 and Table 8, for HDPE and LDPE, respectively, for both training and testing datasets.

Table 7. Comparison of ANN models performances for HDPE

\begin{tabular}{ccccc}
\hline Parameters & Parameters & ANN-Experiment & ANN-Moldex3D & ANN-Moldflow \\
\hline \multirow{3}{*}{ Training } & $M R E$ & 0.011 & 0.011 & 0.018 \\
& $R$ & 1.000 & 1.000 & 0.999 \\
& RMSE & 1.95 & 2.11 & 6.090 \\
\cline { 2 - 5 } Testing & $M R E$ & 0.047 & 0.017 & 0.055 \\
& $R$ & 0.991 & 1.000 & 0.990 \\
& RMSE & 8.97 & 2.71 & 19.46 \\
\hline
\end{tabular}

Table 8. Comparison of ANN models performances for LDPE

\begin{tabular}{ccccc}
\hline Parameters & Parameters & ANN-Experiment & ANN-Moldex3D & ANN-Moldflow \\
\hline \multirow{3}{*}{ Training } & $M R E$ & 0.016 & 0.008 & 0.008 \\
& $R$ & 0.999 & 1.000 & 1.000 \\
& RMSE & 2.68 & 1.49 & 2.53 \\
\cline { 2 - 5 } Testing & $M R E$ & 0.080 & 0.056 & 0.062 \\
& $R$ & 0.945 & 0.996 & 0.946 \\
& $R M S E$ & 15.67 & 8.81 & 38.69 \\
\hline
\end{tabular}

The ANN trained with Moldex3D data is the best-trained network, followed by the ANN trained with experimental data and the one trained with Moldflow data, as shown in Table 7 and Table 8. Based on the $t$-test, we have found that there is no statistically significant difference between the training data obtained by either simulation or experiment and the corresponding values predicted by the ANN model. 
Based on the above analysis, it was concluded that the ANN models are adequate to predict the flow length for both polymers despite the small number of the data used in the training process (for example, only 21 experiments), if the input data are statistically significant.

\subsection{ANN flow length predictions}

Figure 12 shows the comparison between experimental data and the values predicted by ANNExperiment model for the testing dataset, i.e., DOE 3, 8, 12, 17, 21 and 25, respectively. The relative errors between the two approaches, calculated according to Eq. (1), are also depicted in this figure.

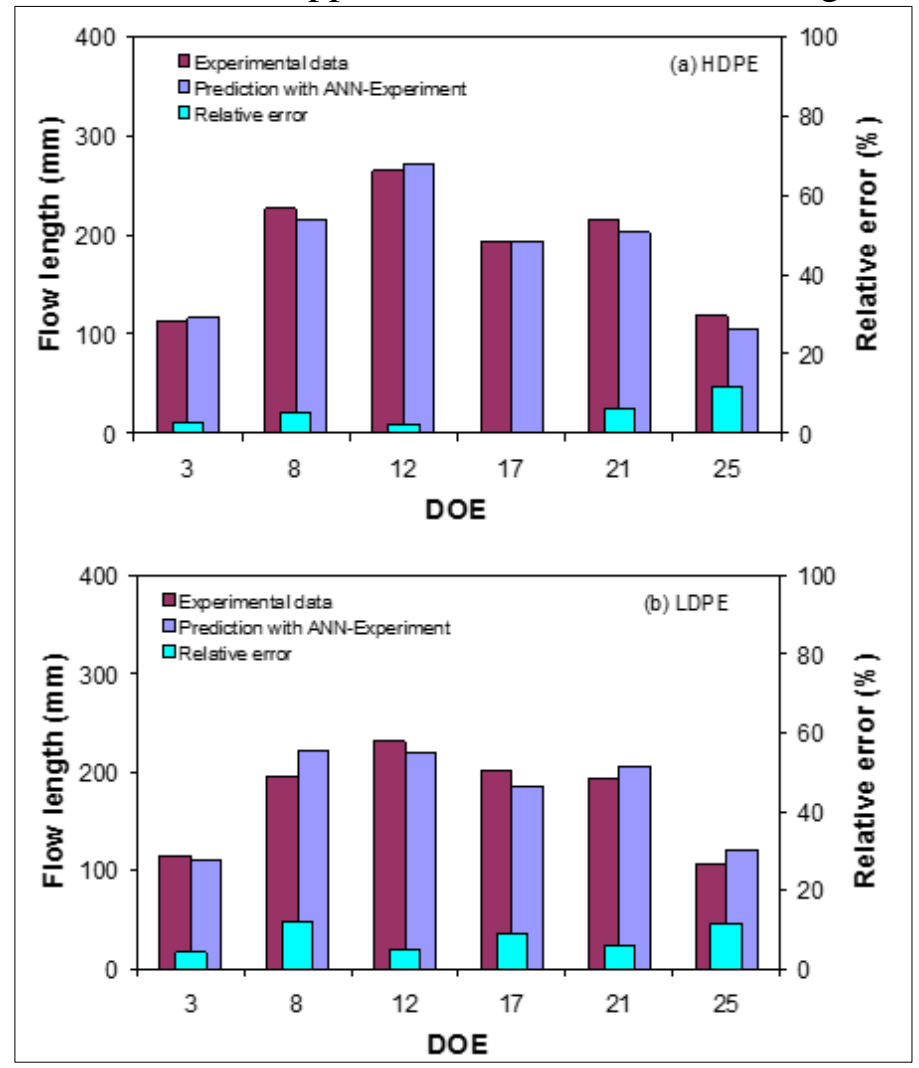

Figure 12. Comparison of flow length between experimental data and ANN-Experiment prediction

As shown in Figure 12, the ANN-Experiment model generated very good predictions with only few over or under fitted results. The $M R E$ testing values obtained from the ANN- Experiment for HDPE and LDPE were $4.7 \%$ and $8 \%$, respectively. The values of $R$ for HDPE and LDPE were found to be 0.991 and 0.945 , respectively, indicating that the ANN-Experiment model has efficiently approximated the experimental values. It was also found that there is no statistically significant difference ( $p$-value is 0.45 for HDPE and 0.47 for LDPE) between the flow length values predicted by the ANN- Experiment and the testing experimentally measured dataset.

Figure 13 shows the comparison between the Moldex3D simulation and the ANN-Moldex3D prediction for the testing dataset, i.e., DOE 3, 8, 12, 17, 21 and 25, respectively. As it is shown in Figure 13, the ANN model trained with Moldex3D simulation data is every good in predicting the behavior of the polymer flow length, except for DOE 25 (LDPE, $1 \mathrm{~mm}$ thickness). In this particular case, the relative error between the predicted and the simulation flow lengths was about $20 \%$. 

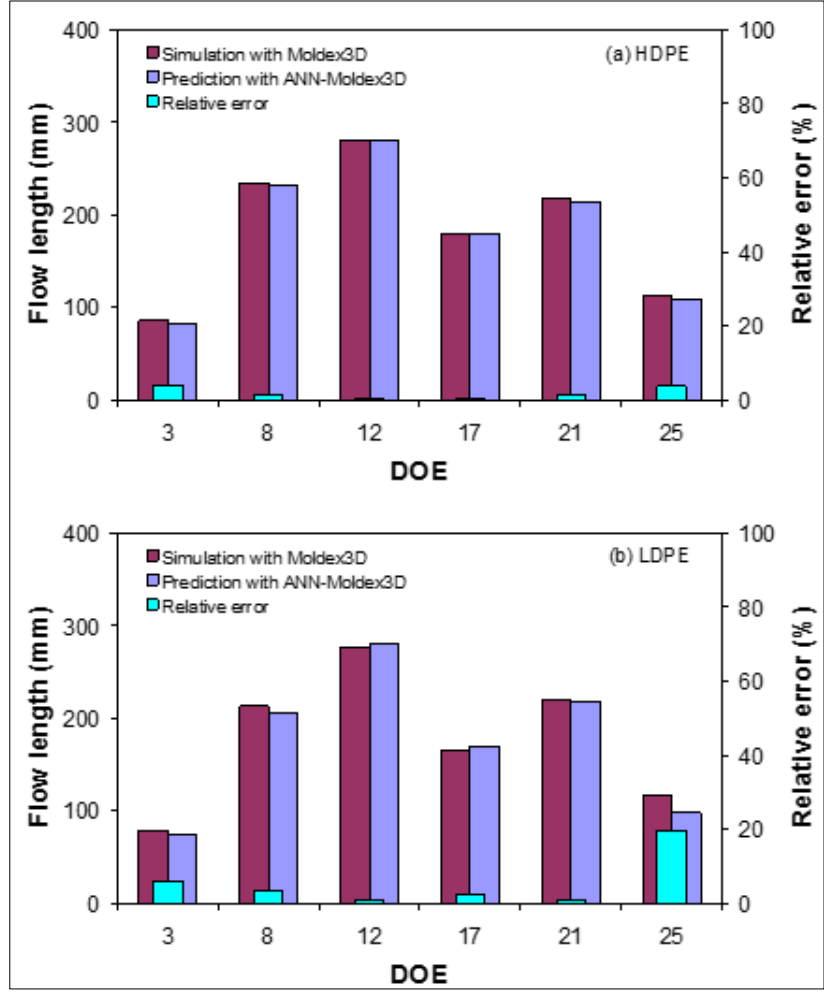

Figure 13. Comparisons of flow length between Moldex3D simulation and ANN-Moldex3D prediction

However, there are no statistically significant differences in flow length between the testing and the ANN-Moldex3D predicted flow lengths ( $p$-value greater than 0.05 for both polymers). Moreover, as shown in Table 7 and Table 8, both the training and the testing MREs were bellow or equal to 5\% indicating that the ANN-Moldex3D model was well trained and fully generalized.
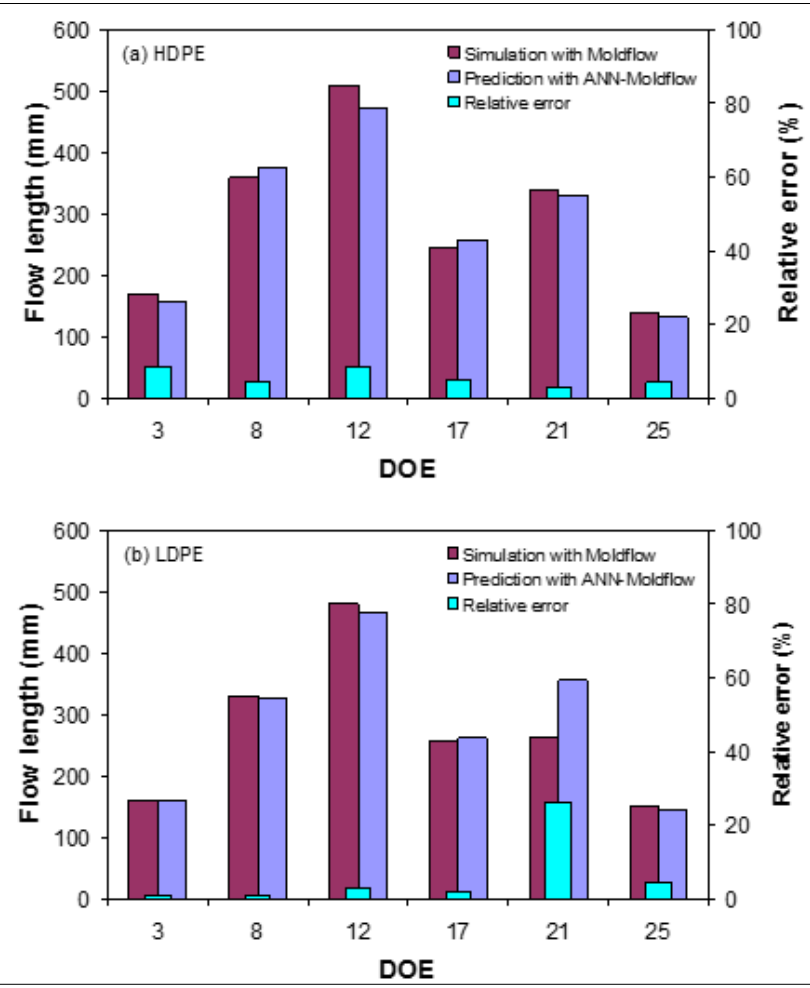

Figure 14. Comparison of flow length between Moldflow simulation and ANN-Moldflow prediction 
Figure 14 shows the comparison between the Moldflow simulation and the ANN-Moldflow prediction for the testing dataset, i.e., DOE 3, 8, 12, 17, 21 and 25, respectively, not used in the training process. As shown in Table 7 and Table 8, the testing MREs are within acceptable limits, i.e., bellow $10 \%$ and therefore the model offers good accurate results. Furthermore, based on the $t$-test, it was found that there are no significant differences between the testing and the predicted flow lengths $(p$-value $=0.47$ and 0.43 for HDPE and LDPE, respectively, greater that 0.05). These results suggest that the ANNMoldflow model was well trained for predicting flow length based on the simulation with Moldflow despite the small number of data. The increase in MRE of ANN-Moldflow as compared with that of ANN-Modex3D is attributed to the fact that the Moldflow simulation gave greater flow length especially for cavities with higher thickness, i.e., $2 \mathrm{~mm}$.

Linear regression analysis was carried out between the flow length predicted by ANNs and their corresponding experimental values for all 27 data in Table 5. As shown in Figure 15, the ANNMoldex3D model shows a significant higher generalization capacity $\left(R^{2}=0.991\right.$ for HDPE and 0.928 for LDPE) than the ANN-Moldflow model $\left(R^{2}=0.859\right.$ for HDPE and 0.815 for LDPE).

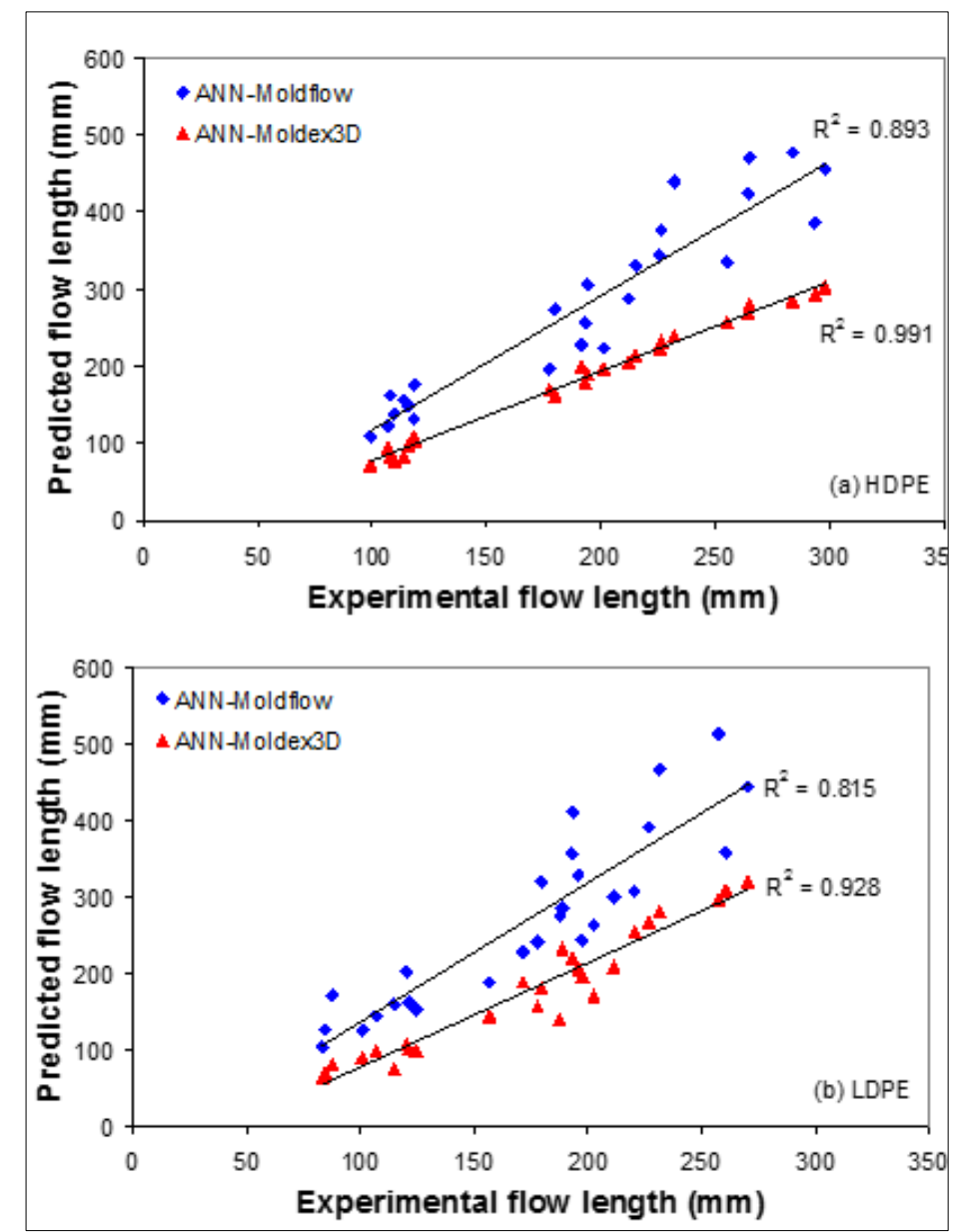

Figure 15. Experimental data versus ANN predictions for flow length

The predicted flow length based on ANN-Moldex3D is very close to the experimental observation, with a reasonable MRE of $10 \%$ for HDPE and 20\% for LDPE. On the other hand, the MRE between the experimental data and ANN-Modflow values is equal to 30\% for HDPE and 35\% for LDPE. These high values for the MRE are caused by the fact that Moldflow overestimates (or underestimates) the flow length as compared with the experimental data, and not because the ANN model is not well trained. 


\section{Conclusions}

This paper discussed the application of CAE technology, such as Moldflow and Moldex3D, and the artificial neural network (ANN) method, for predicting the polymer flow length through a spiral part. A 4-factor 3-level Taguchi $\left(\mathrm{L}_{27}\right)$ orthogonal array was considered for the design of both numerical and injection molding experiments and for the generation of both the training and the testing datasets for the ANN modeling. The processing parameters selected for the injection molding process were melt temperature, mold temperature, injection pressure, and cavity thickness. The optimum ANN architecture was identified based on the trial and error method, and the predictive capabilities of the ANN models were compared based on root mean square error $(R M S E)$, mean relative error $(M R E)$ and correlation coefficient $(R)$.

The key conclusions of this research are:

(1) The best modeling of experimental flow length, from both qualitative and quantitative viewpoints, was obtained with Moldex3D, with an $M R E$ of $5 \%$. The gap between simulation and physical experiments is due to the simplification and approximation assumptions, especially in the case of the Moldflow software, which over-predicts the flow length, as compared with both Moldex3D and experimental results, especially for higher cavity thickness (greater than $1.0 \mathrm{~mm}$ ).

(2) Based on the experimental and simulation results, it was found that the cavity thickness is the most significant factor affecting the polymer flow length. The melt flow length decreases with the reduction of part thickness. Melt temperature is the secondary factor, higher melt temperature being also necessary in the molding process of thin wall plastic parts.

(3) The ANN was applied to predict the LDPE and HDPE flow lengths based on both simulation and experimental data. The ANN models were tested on independent datasets originating from two simulated datasets and one experimental dataset. The ANN models were able to accurately predict the flow length with the MRE of the testing data less than $10 \%$. The ANN-Moldex3D model was found to be more accurate in prediction as compared with the ANN-Moldflow model or the ANN-Experiment model.

(4) The flow length predicted by the ANN model using Moldex3D and Moldflow data were statistically significant, indicating that the combination of ANN and Taguchi design of experiment method leads to a well-trained ANN model without performing many, expensive experiments. However, it can be argued that the use of CAE technologies to generate training data for the ANN model gives good results for the prediction of the flow length, if the CAE effectively simulates the injection molding process. Thus, the predictive ability of the ANN model trained with simulation data must be verified against experimental data.

Acknowledgements: The authors would like to thank Moldex3D for providing the simulation software for this study. The work of Ionut-Laurentiu Sandu was supported by an internal research grant of "Dunarea de Jos" University of Galati, contract number GI04/01.03.2019. The work of Florin Susac, Felicia Stan and Catalin Fetecau was supported by the project "EXPERT", financed by the Romanian Ministry of Research and Innovation, in the framework of Programme 1 - Development of the national research and development system, Sub-programme 1.2 - Institutional Performance - Projects for financing excellence in Research, Development and Innovation, Contract no. 14PFE/17.10.2018.

\section{References}

1. ZARECHIAN, B.A., A quantitative comparison and validation of computer aided engineering softwares simulating the plastics injection molding process, University of Massachusetts Lowell, ProQuest, 2008.

2. GUJRATI, P.D., LEONOV, A.I., Modeling and simulation of polymers, Wiley-WCH, 2010.

3. ZHOU, H., Computer Modeling for Injection Molding: Simulation, Optimization, and Control, Wiley, 2013.

4. FERRY, J.D., Viscoelastic Properties of Polymers, $3^{\text {rd }}$ Edition, New York, Wiley-Interscience, 1980. 
5. DANG, X.P., General frameworks for optimization of plastic injection molding process parameters, Simul. Model. Pract. Th., 41, 2014, 15-27.

6. OZCELIK, B., ERZURUMLU, T., Determination of effecting dimensional parameters on warpage of thin shell plastic parts using integrated response surface method and genetic algorithm, Int. Commun. Heat Mass, 32, 2005, 1085-1094.

7. TZENG C.J., YANG, Y.K., LI, Y.H., A study of optimization of injection molding process parameters for SGF and PTFE reinforced PC composites using neural network and response surface methodology, Int. J. Adv. Manuf. Technol., 63, 2012, 691-704.

8. CHEN, C.P., CHUANG, M.T., HSIAO, Y.H., YANG, Y.K., TSAI, C.H., Simulation and experimental study in determining injection molding process parameters for thin-shell plastic parts via design of experiments analysis, Expert. Syst. Appl., 36, 2009, 10752-10759.

9. OZCELIK, B., ERZURUMLU, T., Minimization of warpage and sink index in injection-molded thermoplastic parts using Taguchi optimization method, Mater. Design. 27, 2006, 853-861.

10. OKTEN, H., ERZURUMLU, T., UZMAN, I., Application of Taguchi optimization technique in determining plastic injection molding process parameters for thin-shell part, J. Mater. Process. Technol., 28, 2007, 1271-1278.

11. SONG, M.C., LIU Z., WANG, M.J., YU, T.M., ZHAO, D.Y., Research on effects of injection process parameters on the molding process for ultra-thin wall plastic parts, J. Mater. Process. Technol.,187 (2), 2007, 668-671.

12. TSAI, K.M., HSIEH, C.Y., LO, W.C. A study of the effects of process parameters for injection molding on surface quality of optical lenses, J. Mater. Process. Technol. 209, 2009, 3469-3477.

13. ALTAN, M., Reducing shrinkage in injection moldings via the Taguchi, ANOVA and neural network methods, Mater. Design. 31, 2001, 599-604.

14. OZCELIK, B., SONAT, I., Warpage and structural analysis of thin shell plastic in the plastic injection molding, Mater. Design. 30, 2009, 367-375.

15. GAO, Y., WANG, X., Surrogate-based process optimization for reducing warpage in injection molding, J. Mater. Process. Technol. 209, 2009, 1302-1309.

16. SHEN, C., WANG, L.Q., LI, Q., Optimization of injection molding parameters using combination of artificial neural network and genetic algorithm method, J. Mater. Process. Technol., 183, 2007, 412418.

17. YARLAGADDA, P.K.D.V., TECK Khong, C.A., Development of a hybrid neural network system for prediction of process parameters in injection moulding, J. Mater. Process. Technol., 118, 2001, 109115.

18. KENIG, S., BEN-DAVID, A., OMER, M., SADEH, A., Control of properties in injection molding by neural networks, Eng. Appl. Artif. Intel., 14, 2001, 819-823.

19. MOK, S.L., KWONG, C.K., Application of artificial neural network and fuzzy logic in a case-based system for initial process parameter setting of injection molding, J. Intell. Manuf., 13, 2002, 165-176.

20. KWAK, T.S., SUZUKI, T., BAE, W.B., UEHARA, Y., OHMORI, H., Application of neural network and computer simulation to improve surface profile of injection molding optic lens, J. Mater. Process. Technol., 170, 2005, 24-31.

21. CHEN, W.C., TAI, P.H., WANG, M.W., DENG, W.J., CHEN, C.T., A neural network-based approach for dynamic quality prediction in a plastic injection molding process, Expert. Syst. Appl., 35, 2008, 843-849.

22. LIAO, X.P., XIE, H.M., ZHOU, Y.J.W., XIA, W., Adaptive adjustment of plastic injection processes based on neural network, J. Mater. Process. Technol., 187-188, 2007, 676-679.

23. YIN, F., MAO, H., HUA, L., GUO, W., SHU, M., Back propagation neural network modeling for warpage prediction and optimization of plastic products during injection molding, Mater. Design, 32, 2011, 1844-1850. 
24. SHI, H., XIE, S., WANG, X., A warpage optimization method for injection molding using artificial neural network with parametric sampling evaluation strategy, Int. J. Adv. Manuf. Technol. 65, 2013, 343-353.

25. OZCELIK, B., ERZURUMLU, C., Comparison of the warpage optimization in the plastic injection molding using ANOVA, neural network model and genetic algorithm, J. Mater. Process. Technol. 171, 2006, 437-445.

26. FETECAU, C, Injectarea materialelor plastice, $2^{\text {nd }}$ Edition, Bucharest, Editura Didactica si Pedagogica, 2007.

27. SEOW, L.W., LAM, Y.C. , Optimizing flow in plastic injection molding, J. Mater. Process. Technol. 72, 1997, 333-341.

28. LIN, H.Y., YOUNG, W.B., Analysis of the filling capability to the microstructures in micro-injection molding, Appl. Math. Model., 33, 2009, 3746-3755.

29. LIN H.Y., CHANG, C.H., YOUNG, W.B, Experimental and analytical study on filling of nano structures in micro injection molding, Int. Commun. Heat Mass, 37, 2010, 1477-1486.

30. MARTINEZ, A., CASTANY, J.D., MERCADO, D., Characterization of viscous response of a polymer during fabric IMD injection process by means a spiral mold, Measurement, 44, 2011, 18061818.

31. AHO, J., SYRJALA, S., Shear viscosity measurements of polymer melts using injection molding machine with adjustable slit die, Polym. Test., 30, 2011, 595-601.

32. MoldFlow Plastic Insight software handbook.

33. KURTARAN, H., OZCELIK, B., ERZURUMLU, T., Warpage optimization of a bus ceiling lamp base using neural network model and genetic algorithm, J. Mater. Process. Technol., 169, 2005, 314319.

34. SPERANZA, V., VIETRI, U., PANTANI, R., Monitoring of injection molding of thermoplastics: Average solidification pressure as a key parameter for quality control, Macromol. Res. 19, 2011, 542554.

35. WANG, J. Some Critical Issues for Injection Molding, Chapter 1 PVT Properties of Polymers for Injection Molding, InTech, 2012.

36. FETECAU, C., STAN, F., POPA, C., A Comparative Numerical Study Regarding The Behaviour of Some Biocompatible Plastic Materials To Injection Moulding, Mater. Plast., 43 (1), 2006, 51-56.

37. FETECAU, C., STAN, F., Computational Prediction of Defects During Injection Molding in Complex Part, Mater. Plast., 44 (3), 2007.

38. FETECAU, C., STAN, F., Analysis and Simulation of the Three-Dimensional Injection Moulding Process of Ultra-High Molecular Weight Polyeethylene, Mater. Plast., 44 (4), 2007.

39. SANDU, I.L., FETECAU, C., Effects of Injection Process parameters om the Warpage of Thinwalled Plastic Parts, Mater. Plast., 48 (4), 2011, 315-321.

40. ROY, R.K., Design of Experiments Using the Taguchi Approach: 16 Steps to Product and Process Improvement, John Wiley \& Sons, 2011.

41. LAPIN, L., Modern Engineering Statistics, Wadsworth Publishing Company, 1997.

42. SUSAC, F., TABACARU, V., TEODOR, V.G., BAROIU, N., Effect of Cutting Parameters on the Hole Quality in Dry Drilling of Some Thermoplastic Polymers, Mater. Plast., 56 (1), 2019, 245-251.

43. SUSAC, F., STAN, F., Experimental Investigation, Modeling and Optimization of Circularity, Cylindricity and Surface Roughness in Drilling of PMMA Using ANN and ANOVA, Mater. Plast., 57 (1), 2020, 57-68.

Manuscript received: 16.06 .2020 